\title{
Results of left ventricular aneurysmectomy with a tailored scar excision and primary closure technique
}

Controversy exists concerning which surgical technique is optimal for ventricular aneurysm repair. In $92(97 \%)$ of 95 patients, we tailored scar excision to remove nonfunctioning wall and restore left ventricular geometry and shape toward normal while allowing linear closure. Preoperative and/or postoperative multiple gated acquisition scans were obtained in $76(83 \%)$ of 92 patients and Doppler echocardiograms in $79(86 \%)$ of 92 . Before operation 78 patients $(85 \%)$ were in New York Heart Association class III or IV with congestive heart failure in $58(63 \%)$, angina in $69(75 \%)$ and syncope in $46(50 \%)$ of the 92 patients. Additional operative procedures included aorta-coronary bypass grafting in 81 patients $(88 \%)$, septoplasty in $4(4 \%)$, and arrhythmia ablation in $54(59 \%)$. Hospital mortality was $3(3 \%)$ of 92 patients. There have been 15 late deaths caused by congestive heart failure with or without mitral regurgitation (7 of 15$)$. Among survivors $66(89 \%)$ of 74 were symptomatically improved with 25 (34\%) of 74 in New York Heart Association class I, 24 (32\%) of 74 in class II, 19 $(26 \%)$ of 74 in class III, and $6(8 \%)$ of 74 in class IV. Actuarial survival was $88 \%, 86 \%$, and $80 \%$ at 1,2 , and 5 years, respectively, and was not different for patients with a preoperative left ventricular ejection fraction less than $20 \%$. In 47 patients with an anterior aneurysm who had preoperative and postoperative studies, multiple gated acquisition scans showed improvement in left ventricular ejection fraction from $23 \%$ to $30 \%(p<0.001)$. Preoperative Doppler echocardiograms showed significant mitral regurgitation ( $2+$ or more) in $26(36 \%)$ of 72 patients studied. Of these, 21 had postoperative studies and mitral regurgitation was improved by at least one grade in $12(57 \%)$ of 21 patients. We conclude that aneurysm repair with a tailored scar excision and linear closure is associated with low operative mortality, objective evidence of improvement in left ventricular function, symptomatic relief, and long-term survival even in patients with advanced left ventricular dysfunction and mitral regurgitation. (J ThoraC Cardiovasc Surg 1994;107:690-8)

Lynda L. Mickleborough, MD, Hiroshi Maruyama, MD, Peter Liu, MD, and Shanas Mohamed, RN, Toronto, Ontario, Canada

For or many years left ventricular (LV) aneurysm resection has been an accepted treatment for congestive heart failure, angina, and thromboembolic complications or as an adjunct for therapy of ventricular arrhythmias. Classic descriptions of the procedure include excision of the

From the Divisions of Cardiovascular Surgery and Cardiology, University of Toronto, Toronto, Ontario, Canada.

Supported by the Canadian Heart Foundation and The Heart and Stroke Foundation of Ontario.

Received for publication May 19, 1993.

Accepted for publication Sept. 14, 1993.

Address for reprints: Lynda L. Mickleborough, MD, Division of Cardiovascular Surgery, EN 13-217, 200 Elizabeth St., Toronto, Ontario M5G 2C4, Canada.

Copyright ${ }^{\odot} 1994$ by Mosby-Year Book, Inc.

$0022-5223 / 94 \$ 3.00+0 \quad \mathbf{1 2} / \mathbf{1} / \mathbf{5 1 7 7 3}$ aneurysm leaving behind a rim of scar to facilitate closure. ${ }^{1}$ In certain centers, on the basis of theoretic considerations of improved LV geometry, linear closure of the defect has been replaced by more complex repair techniques that have included patch repair, ${ }^{2}$ inverted $T$ closure, ${ }^{3}$ the pursestring technique of Jatene, ${ }^{4}$ the endoventricular circular plasty of Dor and associates, ${ }^{5}$ and the endoaneurysmorrhaphy technique of Cooley. ${ }^{6}$ Two clinical studies have compared linear and endoventricular repair with varying results, 7,8 and no prospective trial to date has proved that any of the more complex repair techniques are associated with lower perioperative mortality or improved functional results.

Most published aneurysm series have reported consistent symptomatic improvement in the postoperative state, ${ }^{9-11}$ however, attempts to correlate clinical improve- 


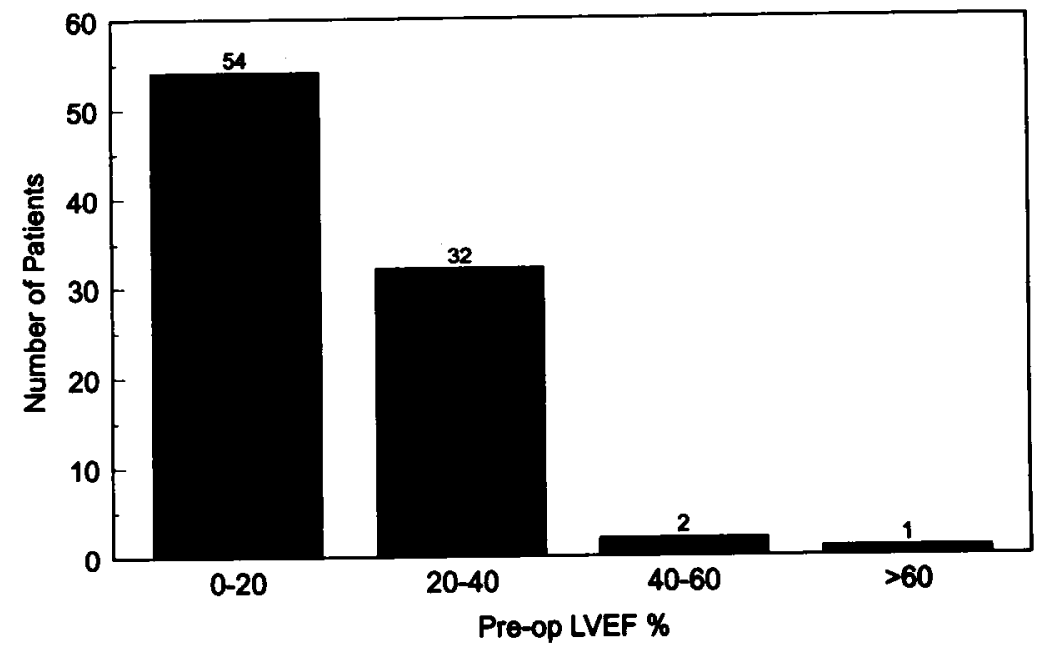

Fig. 1. Histogram showing distribution of preoperative (Pre-op) LVEF among our patient population.

ment with changes in objective assessment of $\mathrm{LV}$ function have yielded inconsistent results. With an ever-increasing population of patients with coronary artery disease, previous infarction, or congestive heart failure with or without mitral regurgitation (MR), and with a limited pool of donor hearts for transplantation, alternate therapies that can alleviate symptoms and prolong survival must be explored. ${ }^{12,13}$

Our approach in such patients has included tailored scar excision followed by suture closure of the defect plus aorta-coronary bypass grafting, whenever possible. We have recently reviewed results obtained with this approach in $92(97 \%)$ of 95 consecutive patients operated on for LV aneurysm between August 1982 and August 1992. In these patients we used modern imaging techniques to provide preoperative and postoperative assessment of LV function and morphology and Doppler echocardiographic assessment of mitral valve function to gain insights into the results achieved with this operative technique.

\section{Materials and methods}

Patient population. In the past 10 years, 95 patients underwent LV aneurysm resection by a single staff surgeon at the University of Toronto. In all but three cases, tailored excision of scar was followed by suture closure. A Dacron patch was necessary to close the defect in the other three patients, who have been excluded from this analysis. The patients ranged in age from 34 to 78 years (mean $58 \pm 9$ years). There were 16 women and 76 men. Eighty-three aneurysms were anterior $(90 \%)$ and nine $(10 \%)$ were posterior in location. Significant calcification of the wall was present in $11 \%$ (10 of 92). Indications for operation were angina in $75 \%$ (69 of 92), congestive heart failure in $63 \%$ ( 58 of 92), and ventricular arrhythmias in $59 \%$ ( 54 of 92). Most patients were in New York Heart Association
(NYHA) class III or IV before operation. Double or triple vessel disease was present in $77 \%$ (71 of 92). Associated cardiac procedures included coronary artery bypass grafting in $88 \%(81$ of 92 ), patch septoplasty in $4 \%$ (4 of 92), and arrhythmia ablation (endocardial excision plus cryoablation) in 59\% (54 of 92). The distribution of ejection fraction (EF) in our preoperative patient population is shown in Fig. 1. Ninety-three percent $(86$ of 92) had an EF of less than $40 \%$ and the mean preoperative EF was $23 \% \pm 9 \%$ (range $7 \%$ to $48 \%$ ).

Operative procedure: tailored scar excision and primary closure. With the patient supported by cardiopulmonary bypass at normothermia, the heart was carefully examined. If there was any doubt that the infarct area was significantly thinned, aspiration with an 18-gauge needle was done to determine wall thickness. A ventricular vent was not inserted until after the aneurysm had been opened and all clot carefully removed. With the heart open and beating, the size and shape of the nonaneurysmal chamber was carefully evaluated. When the chamber outside the aneurysm was of relatively normal size and shape, resection of scar was followed by linear closure, as described in the literature. ${ }^{1}$ In patients with marked chamber dilation, diffuse hypokinesis, and gross distortion of ventricular shape (spherical versus conical) it is not possible with any repair technique to restore the ventricular cavity to normal size and shape (Fig. 2). In these patients, for linear closure to be done without distorting internal geometry, specifically the relationship between the papillary muscles and the septum, a portion of the nonfunctioning wall had to be left behind. In such cases excision was planned to remove nonfunctioning wall and to restore ventricular size and shape toward normal, as much as possible, while still allowing linear closure. In patients who have endocardial calcification that extends beyond the planned area of resection, excision of the calcified layer facilitates approximation of the walls in the repair. In many cases the excised specimen was composed of a mixture of infarcted and viable muscle, and it was not possible to leave a rim of fibrous scar for closure, as mentioned in the classic description of aneurysm repair. ${ }^{1}$ In these cases sutures had to be placed through fairly thick areas of myocardium. In most cases closure of the defect was done before cardioplegic arrest. 


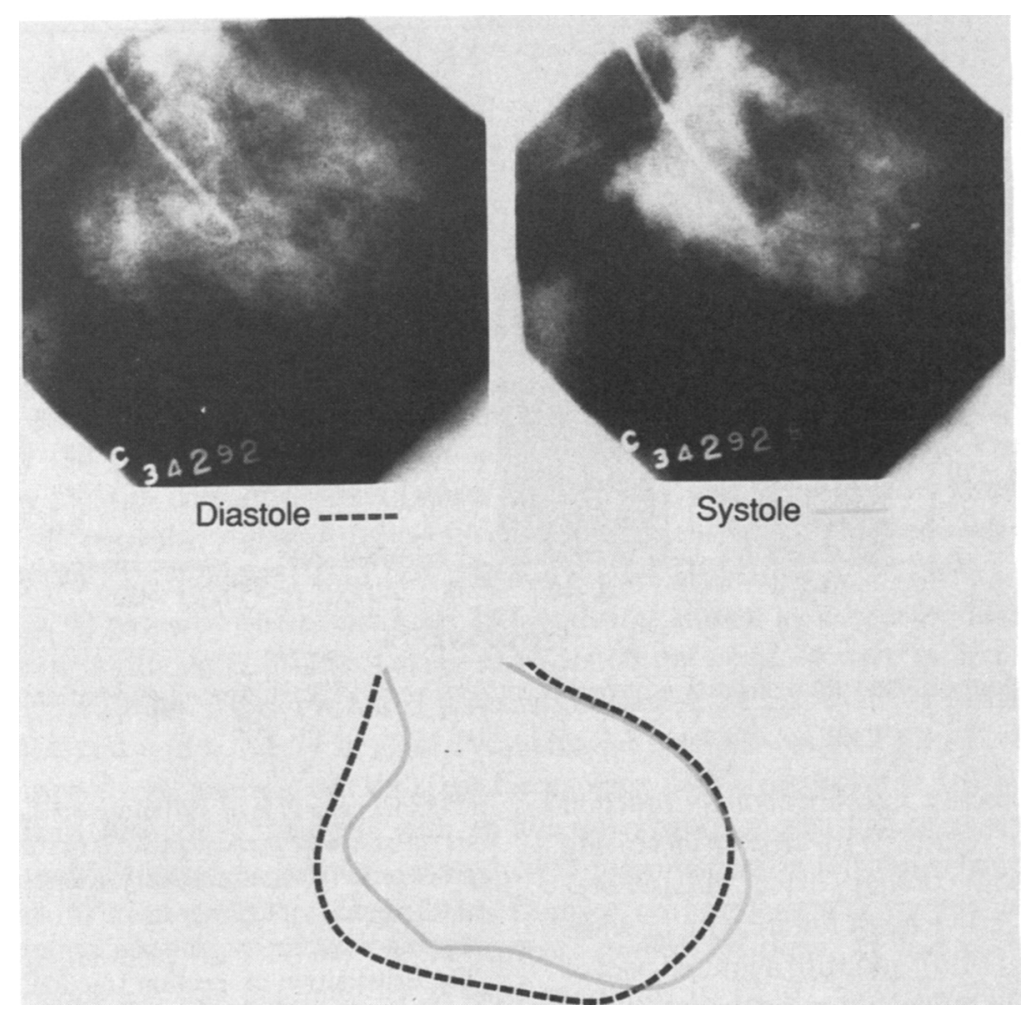

Fig. 2. Representative diastolic and systolic frames from ventriculogram of patient in this series. Ventricular wall is diffusely hypokinetic. Chamber is markedly dilated and distorted.

In patients with a history of symptomatic ventricular arrhythmias who had inducible ventricular tachycardia on preoperative electrophysiologic testing, directed endocardial excision and cryoablation were done in regions indicated by mapping. In the few cases in which a septal site of origin was suspected, the patient was cooled and the heart arrested with cold cardioplegic solution before cryoprobe application to allow deeper penetration of the lesion.

In cases in which the septum was aneurysmal or thinned by extensive resection of endocardial scar, a patch septoplasty was done with glutaraldehyde-fixed bovine pericardium. ${ }^{14}$ The patch was sewn in place with 4-0 Prolene sutures (Ethicon, Inc., Somerville, N.J.) and incorporated anteriorly into the repair. Closure of the defect was done with interrupted Prolene mattress sutures buttressed with felt strips. Sutures were placed farther apart on the tissue than on the felt, so that the length of the incision was plicated by about $25 \%$ in the closure (Fig. 3 ). This helps restore the shape of the ventricle toward normal. The closure was then reinforced with a continuous suture to obtain hemostasis. Elimination of air was done through the suture line as the closure was completed and via a superior pulmonary vein vent before the patient was weaned from bypass. Once closure was completed, if aorta-coronary bypass grafting was indicated, the patient was cooled, a crossclamp was applied, and cold blood cardioplegic solution was infused.

Follow-up. Follow-up was completed by means of telephone contact with the patient or referring physician and office visits when indicated. To assess the influence of the procedure on $\mathrm{LV}$ function, preoperative and postoperative multiple gated acquisition (MUGA) scans were obtained in 51 (55\%) of 92 patients. LV EF was calculated by computerized analysis. Doppler echocardiographic studies were done in $79(86 \%)$ of 92 patients by either the transthoracic or transesophageal approach. In 54 (59\%) of 92 patients both preoperative and postoperative studies (1 week after operation) were obtained. MR was assessed and graded. Studies were of sufficient quality to allow detailed analysis of regional wall motion or determination of $\mathrm{LV}$ dimensions in only $29(37 \%)$ of 79 patients.

Statistical analysis. Actuarial survival was calculated by the Kaplan-Meier statistics. A Wilcoxon test was used to evaluate differences in survival among subgroups of patients. Paired $t$ test was used to evaluate differences in EF and LV dimensions before and after operation. $\chi^{2}$ Statistics, Fisher's exact test, and analysis of variance with Duncan's multiple range test were used to assess whether symptomatic status after operation (NYHA class) was related to EF, end-diastolic dimension, or degree of MR after operation.

\section{Results}

All patients in this series were successfully weaned from bypass, although 17 (18\%) of 92 required intraaortic balloon pump insertion for perioperative support.

There were three hospital deaths, for an operative mortality rate of $3 \%$. Two of these were related to adult 

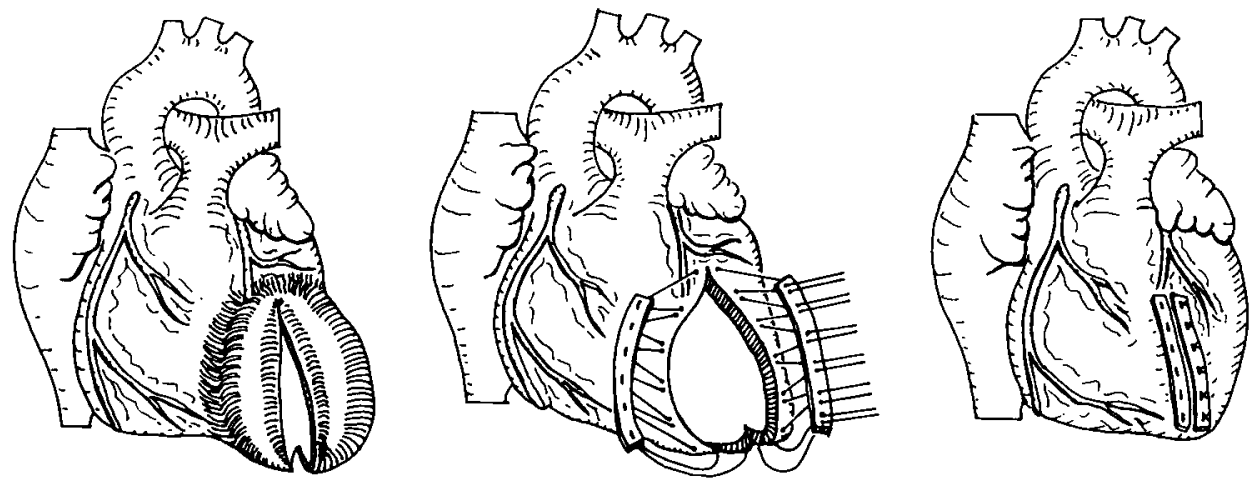

Fig. 3. Diagram showing preoperative appearance and suture closure technique that results in plication of repair to restore more normal shape to ventricle. Each mattress suture incorporates wider distance on edge of $L V$ resection than it does on felt strips. When sutures are tied, resection margins are plicated in longitudinal direction, which restores LV size and shape toward normal. Additional continuous suture is later added to obtain hemostasis.

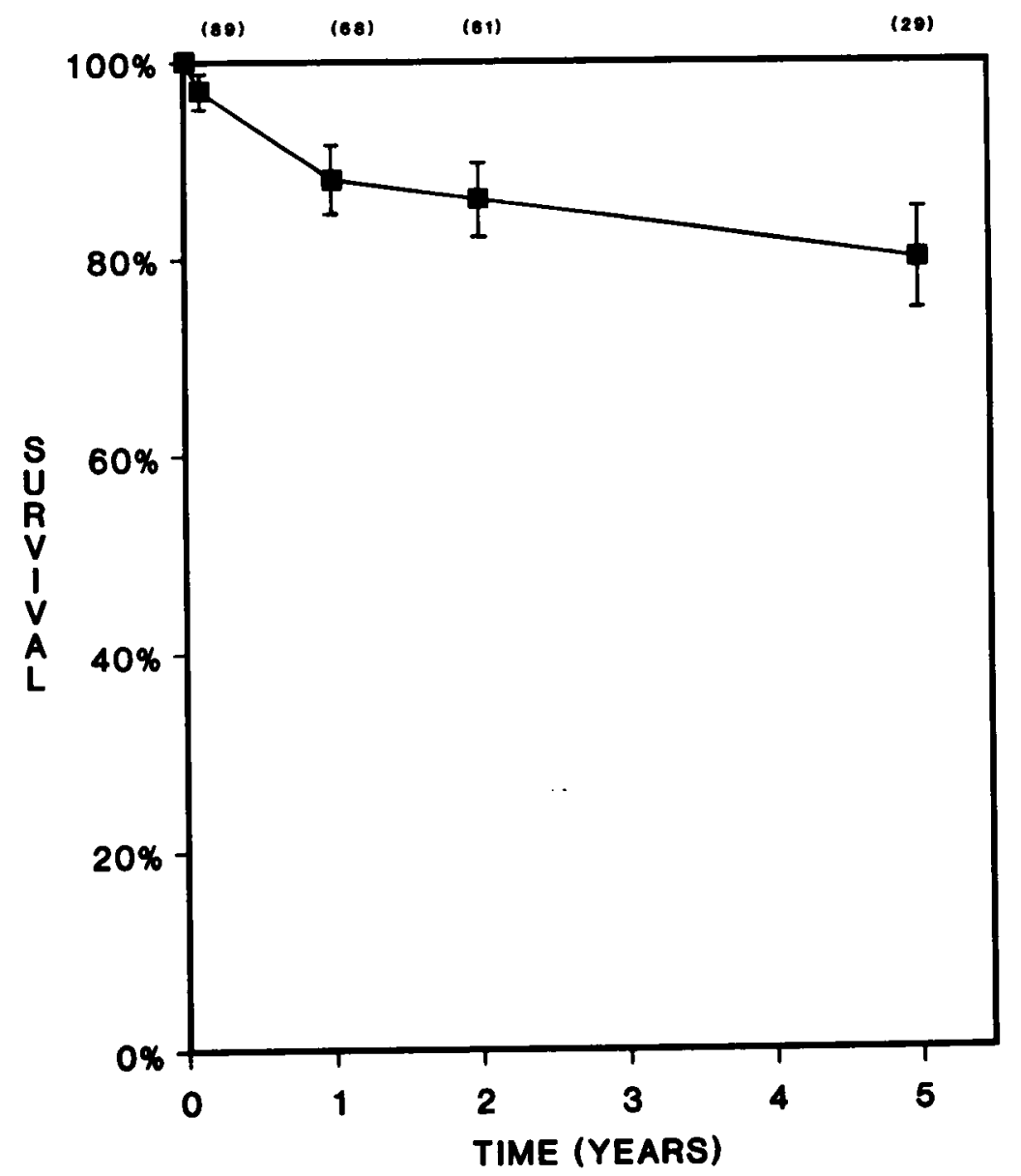

Fig. 4. Actuarial survival after LV aneurysm resection. Figures in parenthesis at top indicate number of patients left at risk at that time of follow-up.

respiratory distress syndrome in patients who had been receiving long-term amiodarone therapy. The additional death was due to congestive heart failure and sepsis in a high-risk patient. No patient required reoperation for bleeding and there were no sternal infections in this series. One patient had a perioperative stroke from which he made a complete recovery.

During follow-up, which extended to 10 years, there 
NYHA

Class

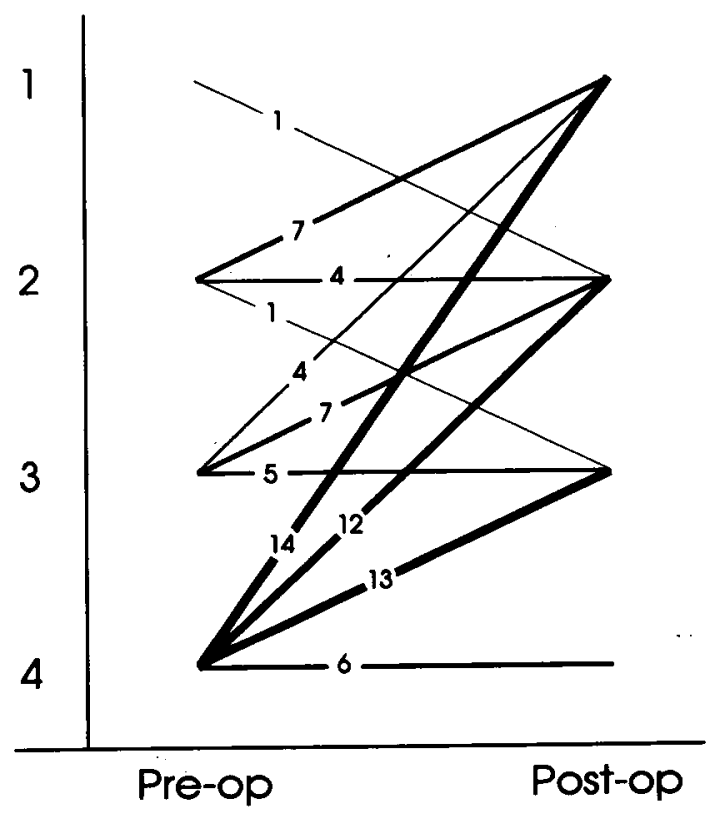

Fig. 5. Preoperative (Pre-op) and postoperative (Post-op) congestive heart failure status (NYHA).

were 15 late deaths as a result of congestive heart failure. The actuarial survival curve including hospital deaths is shown in Fig. 4. The survival was $88 \%$ at 1 year, $86 \%$ at 2 years, and $80 \%$ at 5 years. There was no difference in survival between patients with a preoperative $E F$ of greater than $20 \%$ and those with an EF of less than $20 \%$. However, patients who had symptoms of congestive heart failure on presentation had poorer survival than those who did not $(p=0.005)$.

During follow-up, two patients required transplantation because of increasing symptoms of congestive heart failure (at 15 and 105 months). Two additional patients underwent successful mitral valve replacement for control of symptoms (at 10 and 11 months). In one patient who had no history of arrhythmias ventricular tachycardia developed during follow-up and insertion of an automatic implantable cardioverter-defibrillator device (at 6 months) was necessary.

Functional assessment. Among the survivors ( 66 of $74,89 \%$ ) were symptomatically improved at the most recent follow-up, with 25 (34\%) of 74 in NYHA class I and 24 (32\%) of 74 in NYHA class II. Fig. 5 shows the change in symptom status among survivors.

MUGA assessment before and after operation was available in $47(57 \%)$ of 82 patients with an anterior aneurysm. Average EF before operation was $23 \% \pm 9 \%$
Pre-op Study

performed in $72 / 92$ (78\%)

Post-op

Study
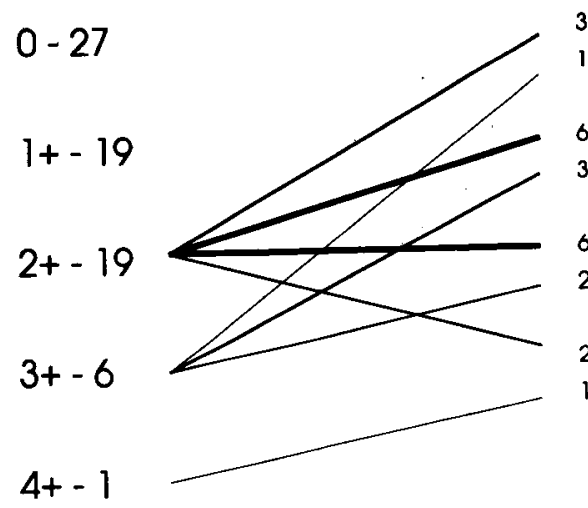

0

$1+$

$2+$

$3+$

$4+$

Fig. 6. Results of preoperative (Pre-op) and early postoperative (Post-op) assessment. MR has been graded on scale of $1+$ to $4+$.

and after operation was $30 \% \pm 10 \%$. The average increase in EF was $7 \%$, which represents a statistically significant improvement $(p<0.001)$. By analysis of variance, there was no relationship between postoperative $\mathrm{EF}$ (as assessed by MUGA scans) and NYHA class during follow-up $(p=0.78)$.

Preoperative Doppler echocardiographic studies showed significant MR (2+ or more) in $26(36 \%)$ of 72 patients studied (Fig. 6). Of these 26 patients, 21 had postoperative studies done and MR was improved by at least one grade in $12(57 \%)$ of 21 . By $\chi^{2}$ statistics, postoperative MR (as assessed by echocardiography in 43 patients) was related to postoperative NYHA class. This relationship was statistically significant $(p=0.04)$ despite the small number of patients studied.

The quality of echocardiographic studies allowed detailed analysis of LV dimensions in only 29 (37\%) of 79 patients. End-diastolic dimension decreased from $61.4 \pm 9.8 \mathrm{~mm}$ before operation to $53.4 \pm 9.0 \mathrm{~mm}$ after operation $(p=0.0002)$ and end-systolic dimensions decreased from $48.8 \pm 8.3 \mathrm{~mm}$ before operation to $40.8 \pm 9.6 \mathrm{~mm}$ after operation $(p=0.0001)$. By analysis of variance, there was no statistically significant relationship between postoperative end-diastolic dimension and NYHA class $(p=0.30)$.

\section{Discussion}

It is difficult, without complex analysis, to compare results obtained in this series with those of other surgical series, or with results of medical treatment in patients with suspected aneurysms, because of the heterogeneity in criteria used to define the presence of an aneurysm.

Pathologically, an aneurysm is an area of previous 
transmural infarction that has become scarred and thinned. Angiographically, an aneurysm is an area of the ventricle that is clearly demarcated from the surrounding chamber by hypokinesis, akinesis, or dyskinesis. ${ }^{15-17}$ In the operating room, an area that appears "aneurysmal" on the angiogram may consist of an obvious dyskinetic sac of thin scar or it may correspond to a region composed of a mixture of scar and viable muscle that may or may not be thinned. The degree of thinning is often not apparent until the chamber has been completely decompressed by the use of cardiopulmonary bypass or after insertion of an LV vent.

In this series, an aneurysm was defined at the time of operation as an area of previously infarcted LV wall that had undergone remodeling and significant thinning as assessed by needle aspiration. We believe this technique is associated with a lower risk of embolization than insertion of an LV vent. If the area that appeared "aneurysmal" on the angiogram was found to consist of a thick wall of myocardium mixed with scar, no resection was done. In these cases revascularization, which might lead to significant improvement in regional wall motion and global ventricular function, ${ }^{18}$ was done whenever possible.

In this series, satisfactory results were obtained with the use of scar excision tailored to suit the anatomy in each patient, followed by linear closure. With this technique, there has been no incidence of failure to wean from bypass or evidence of obvious distortion of LV geometry. By resecting nonfunctioning wall, and plicating the length of the excision in the repair, we have tried to accomplish the goals outlined by Jatene ${ }^{4}$ and Rao and associates ${ }^{19}$ : to decrease chamber dimensions, which decreases wall tension and wall stress, ${ }^{20-22}$ and to redirect normal muscle bundles (as much as possible) to their original position and orientation. ${ }^{4,11,20-26}$ In our series, septal dysfunction was addressed by patch septoplasty versus septal plication as advocated by Jatene. ${ }^{4}$ Septoplasty avoids paradoxic movement of the infarcted septum, while at the same time allowing repair to be accomplished without the need for crossclamping or cardioplegic delivery. We agree with Jaten $\mathrm{e}^{4}$ that operating on the beating heart makes it easier to decide on limits of resection and proper orientation for suture closure.

The operative approach used in this series is not a new technique. It represents a modification of standard scar excision and linear closure as described by Cooley and associates. ${ }^{1}$ Our modifications include lengthwise plication of the closure, as shown in Fig. 3, excision of endocardial calcification when needed to allow linear closure, and excision of nonfunctioning wall guided not only by distribution of scar, but also by consideration of chamber geometry and attempts to optimize the chamber geometry and size that will result from simple closure. Resection of nonfunctioning wall is also tailored to retain relatively normal spatial relationships between the papillary muscles and the septum.

Our technique is not suitable for all patients with a LV aneurysm. In two patients excluded from this series, once the specimen had been removed the resulting circular defect was fixed because of extensive calcification of the surrounding wall and linear closure was simply not possible. The defect was closed with a Dacron patch. In the third patient excluded from this series, a large inferior aneurysm had resulted in extreme thinning of tissue up to the base of the posterior papillary muscle. There was no residual tissue between the posterior septum and the papillary muscle suitable for closure. A patch was inserted to avoid obvious distortion of the subvalvular apparatus, which would have occurred if simple closure had been attempted. The technique described in this paper would also be inappropriate in patients with aneurysms resulting from acute infarction or with aneurysms associated with more complex defects such as septal or free wall rupture. In these cases friability of the surrounding tissue would demand more complex repair techniques such as endoaneurysmorrhaphy described by Cooley ${ }^{6}$ and Komeda and Mickleborough. ${ }^{27}$

One important advantage of the tailored excision and linear closure technique is that in the majority of patients, the entire repair can be done without aortic crossclamping or cardioplegic arrest. By minimizing ischemic time, perioperative mortality and postoperative morbidity may be decreased. We used cold potassium cardioplegic solution to arrest the heart during aorta-coronary bypass grafting to allow precise anastomosis and endarterectomy or vein patch angioplasty when required. We have avoided continuous warm blood cardioplegia, as advocated by other surgeons in Toronto, because we believe that ischemia results whenever the cardioplegic solution is shut off to facilitate construction of the distal anastomoses.

In our cases, we have tailored scar excision to leave the proximal segment of the left anterior descending artery for revascularization whenever possible, even if the distal vessel has been included in the repair. We agree with others that revascularization of even a small portion of the septum may be important in improving short-term and long-term results in these patients. ${ }^{28}$

The hospital mortality rate in our series was low (3\%), despite a high proportion of patients with diffuse coronary artery disease, advanced LV dysfunction, and ventricular arrhythmias. Elefteriades and associates, ${ }^{29}$ using a linear repair technique, reported a mortality rate of $6.7 \%$. Jatene $^{4}$ and Dor ${ }^{5}$ and Komeda ${ }^{3}$ and their associates, using more complex repair techniques, reported operative mor- 
tality rates of $5 \%, 6.2 \%$, and $6 \%$, respectively. Mills, Everson, and Hockmuth ${ }^{30}$ reported an operative mortality rate of $3.3 \%$ using an endoventricular repair technique.

In this series there were few perioperative complications and only $18 \%$ of patients required intraaortic balloon support. This can be compared with $65 \%$ of patients in the series reported by Elefteriades and associates. ${ }^{29}$ No patients required reoperation for bleeding or sternal wound complications. There was only one perioperative stroke. Like Elefteriades and associates ${ }^{29}$ we believe that removing endocardial thrombus before insertion of an LV vent may contribute to the low perioperative stroke rate. We have not had any early or late infections of the repair site. In our entire aneurysm experience, only one late infection was associated with a Dacron patch used to close a posterior wall defect.

In this series, objective evidence of improved LV function after operation was provided by MUGA data. In addition, echocardiographic data available in a limited number of patients showed a significant decrease in LV dimensions and decreased MR after operation. By analysis of variance there was no statistically significant relationship between postoperative EF (as assessed by MUGA) and NYHA class. Others have shown a similar lack of correlation between functional class (exercise capacity) and indices of resting LV performance in patients with heart failure. ${ }^{31}$ There are several possible explanations for this lack of correlation. First, it may reflect the lack of sensitivity of methods used for functional assessment after operation. Global ejection fraction, as determined by nuclear angiography, may be inaccurate because only volumes at end-diastole and end-systole are considered in the calculation. ${ }^{17,32,33}$ More precise Fourier phase and amplitude analysis may be required to reliably assess contractile function after operation..$^{32}$ Second, ejection phase indices do not reflect improvement in diastolic function, which may be related to significant changes in symptom status. Improvement in diastolic function depends on the mechanical properties of the resected tissue, which can be highly variable. ${ }^{34-38}$ Third, it is impossible to sort out the beneficial effects of revascularization from those of aneurysm repair. Symptomatic improvement related to decreased ischemia may or may not be reflected in concomitant changes in LV function.

We also did not find any relationship between postoperative ventricular size (end-diastolic dimension) and functional class after operation. The number of patients in whom diastolic dimensions were available was limited. However, four of five patients whose postoperative enddiastolic dimension was greater than $60 \mathrm{~mm} \mathrm{Hg}$ were in NYHA class I or II. In these patients with global hypokinesis in whom ventricular dilation is a compensatory mechanism, it was impossible to decrease the LV size to normal by the repair process, yet good functional results were achieved.

Others have indicated that $M R$ in association with an LV aneurysm significantly increases the risk of operative intervention. ${ }^{29,}{ }^{39}$ In our patients, preoperative Doppler echocardiographic studies often indicated 1 to $2+$ MR where none was suspected on the angiogram (Fig. 6). In three patients with 3 to $4+\mathrm{MR}$ before operation, who needed intraoperative mapping and ablation of ventricular tachycardia, we were reluctant to add mitral valve replacement to an already complex surgical procedure. In these three patients, repair resulted in a significant decrease in MR. This improvement in mitral valve function may have been due to (1) decreased dilation of the anulus secondary to decreased LV size, (2) improved function of ischemic papillary muscles with revascularization, or (3) realignment of papillary muscles associated with LV repair. After operation there was a statistically significant relationship between the degree of MR (as assessed by echocardiogram) and the NYHA functional class of the patient. This relationship emphasizes the importance of preserving mitral valve function while doing LV repair.

After ventricular repair, close follow-up and careful adjustment of medication is necessary to optimize symptomatic improvement. In our series, five patients required additional surgical procedures to control increasing symptoms of congestive heart failure. In one patient who had never had a history of ventricular arrhythmias, troublesome ventricular tachycardia developed during followup, and insertion of an automatic implantable cardioverter-defibrillator device was necessary. No other patient had significant ventricular arrhythmias during follow-up.

In recent years, the number of patients referred for aneurysm resection has decreased. This may in part be because of successful treatment of acute infarction with thrombolysis. After infarction, aggressive medical management including angiotensin-converting enzyme inhibitors is effective in controlling symptoms of congestive heart failure, and patients live longer before gross myocardial decompensation occurs. However, once decompensation begins, deterioration may be rapid, and patients may die before appropriate investigations can be done and the possibility of surgical intervention entertained. Patients in whom aneurysms develop after infarction should be followed up closely and considered for operation when signs of decompensation occur (increasing symptoms while receiving optimal medical management or increasing diastolic dimensions, increasing $\mathrm{MR}$, or decrease in EF) and before they reach the stage in which transplantation is the only reasonable option. As our series has demonstrated, LV aneurysm resection can be done 
with a low operative mortality, good symptomatic improvement, and an excellent 5-year survival. We believe these results support more liberal recommendations for aneurysm repair.

We thank Ms. Hilary Vincent for the excellent preparation of the manuscript.

\section{REFER ENCES}

1. Cooley DA, Collins HA, Morris GC, Chapman DW. Ventricular aneurysm after myocardial infarction: surgical excision with use of temporary cardiopulmonary bypass. JAMA 1958;167:557-60.

2. Daggett WM, Guyton RA, Mundth ED, et al. Surgery for post-myocardial infarct ventricular septal defect. Ann Surg 1977;186:260-71.

3. Komeda M, David TE, Malik A, Ivanov J, Sun Z. Operative risks and long-term results of operation for left ventricular aneurysm. Ann Thorac Surg 1992;53:22-9.

4. Jatene AD. Left ventricular aneurysmectomy. J THORAC CARDIOVASC SURG 1985;89:321-31.

5. Dor V, Saab M, Coste P, Kornaszewski M, Montiglio F. Left ventricular aneurysm: a new surgical approach. J THORAC Cardiovasc Surg 1989;37:11-9.

6. Cooley DA. Ventricular endoaneurysmorrhaphy: a simplified repair for extensive postinfarction aneurysm. J Cardiac Surg 1989;4:200-5.

7. Cooley DA. Repair of post-infarction aneurysm of the left ventricle. In: Cooley DA, ed. Cardiac surgery: state of the art reviews. Vol. 4, No. 2. Philadelphia: Handley and Belfus, 1990:309.

8. Kesler KA, Fiore AC, Naunhein KS, et al. Anterior wall left ventricular aneurysm repair: a comparison of linear versus circular closure. J THORAC Cardiovasc SURG 1992;103:841-8.

9. Favaloro RG, Effler DB, Groves LK, Westcott RN, Suares E, Lozada J. Ventricular aneurysm: clinical experience. Ann Thorac Surg 1968;6:227-45.

10. Hazan E, Bloch G, Rioux C, Louville Y, Cirotteau Y, Mathey J. Surgical treatment of aneurysm and segmental dyskinesia of the left ventricular wall after myocardial infarction. Am J Cardiol 1973;31:708-1 1.

11. Fisher VJ, Alvarez AJ, Shah A, Dolgin M, Tice DA. Left ventricular scars: clinical and hemodynamic results of excision. Br Heart J 1974;36:132-8.

12. Kron IL. When does one replace the heart in ischemic cardiomyopathy? Ann Thorac Surg 1993;55:581.

13. Luciani GB, Faggian G, Razzolini R, Livi U, Bortolotti U, Mazzucco A. Severe ischemic left ventricular failure: coronary operation or heart transplantation. Ann Thorac Surg 1993;55:719-23.

14. Komeda M, Fremes SE, David TE. Surgical repair of postinfarction ventricular septal defect. Circulation 1990; 82(Suppl):IV243-7.

15. Mangschau A. Akinetic versus dyskinetic left ventricular aneurysms diagnosed by gated scintigraphy: difference in surgical outcome. Ann Thorac Surg 1989;47:746-51.

16. Cohen M, Packer M, Gorlin R. Indications for left ventricular aneurysmectomy. Circulation 1983;67:717-22.

17. Taylor NC, Barber R, Crossland P, Wraight EP, English TAH, Petch MC. Does left ventricular aneurysmectomy improve ventricular function in patients undergoing coronary bypass surgery? Br Heart J 1985;54:145-52.

18. Brundage BH, Massie BM, Botvinick EH. Improved regional wall ventricular function after successful surgical revascularizaiton. J Am Coll Cardiol 1984;3:902-8.

19. Rao G, Zikria EA, Miller WH, et al. Experience with sixty consecutive ventricular aneurysm resections. Circulation 1974;49(Suppl):II149-53.

20. Nicolosi AC, Spotnitz HM. Quantitative analysis of regional systolic function with left ventricular aneurysm. Circulation 1988;78:856-62.

21. Louagie Y, Alouini T, Lesperance J, Pelletier LC. Left ventricular aneurysm with predominating congestive heart failure: a comparative study of medical and surgical treatment. J ThORAC CARDIOVASC SURG 1987;94:571-81.

22. Dymond DS, Stephens JD, Stone DL, Elliott AT, Rees GM, Spurrell RAJ. Combined exercise radionuclide and hemodynamic evaluation of left ventricular aneurysmectomy. Am Heart J 1982;104:977-87.

23. Froehlich RT, Falsetti HL, Doty DB, Marcus ML. Prospective study of surgery for left ventricular aneurysm. Am J Cardiol 1980;45:923-31.

24. Arvan S, Badillo P. Contractile properties of the left ventricle with aneurysm. Am J Cardiol 1985;55:338-41.

25. Hutchins GM, Brawley RK. The influence of cardiac geometry on the results of ventricular aneurysm repair. Am J Pathol 1980;99:221-30.

26. Hutchins GM, Bulkley BH, Moore GW, Piasio MA, Lohr FT. Shape of the human cardiac ventricles. Am J Cardiol 1978;41:646-54.

27. Komeda M, Mickleborough LL. Concealed rupture of the left ventricle with successful surgical repair: case report. Ann Thorac Surg 1993 [In press].

28. Akins $\mathrm{CW}$. Resection of left ventricular aneurysm during hypothermic fibrillatory arrest without aortic occlusion. $\mathbf{J}$ THORAC CARDIOVASC SuRG 1986;91:610-8.

29. Elefteriades JA, Solomon LW, Salazar AM, Batsford WP, Baldwin JC, Kopf GS. Linear left ventricular aneurysmectomy: modern imaging studies reveal improved morphology and function. Ann Thorac Surg 1993;56:242-52.

30. Mills NL, Everson CT, Hockmuth DR. Technical advances in the treatment of left ventricular aneurysm. Ann Thorac Surg 1993;55:792-800.

31. Franciosa JA, Park M, Levine TB. Lack of correlation between exercise capacity and indexes of resting left ventricular performance in heart failure. Am J Cardiol 1981;47:33-9.

32. Yiannikas J, MacIntyre WJ, Underwood DA, et al. Prediction of improvement in left ventricular function after ventricular aneurysmectomy using Fourier phase and amplitude analysis of radionuclide cardiac blood pool scans. Am J Cardiol 1985;55:1308-12. 
33. Shaw RC, Ferguson TB, Weldon CS, Connors JP. Left ventricular aneurysm resection: indications and long-term follow-up. Ann Thorac Surg 1978;25:336-9.

34. Mickleborough LL, Usui A, Downar E, Harris L, Parson I, Gray G. Transatrial balloon technique for activation mapping during operations for recurrent ventricular tachycardia. J Thorac Cardiovasc SuRg 1990;99:227-33.

35. Gorlin R, Klein MD, Sullivan JM. Prospective correlative study of ventricular aneurysm: mechanistic concept and clinical recognition. Am J Med 1967;42:512-31.

36. Parmley WW, Chuck L, Kibowitz C, Matloff JM, Swan
HJC. In vitro length-tension relations of human ventricular aneurysm: relation of stiffness to mechanical disadvantage. Am J Cardiol 1973;32:889-94.

37. Klein MD, Herman MV, Gorlin R. A hemodynamic study of left ventricular aneurysm. Circulation 1967;35:612-30.

38. Tyson K, Mandelbaum I, Shumacker HB. Experimental production and study of left ventricular aneurysms. J THORAC Cardiovasc SuRg 1962;44:731-7.

39. Berry DW, Vauthey JN, Snyder D, et al. The approach to large left ventricular aneurysms: a report of three difficult cases. J Cardiovasc Surg 1988;29:658-62. 